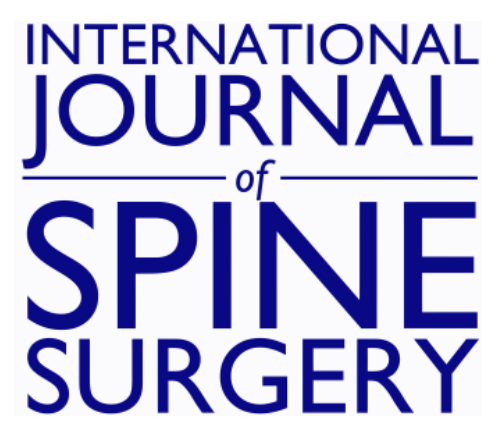

\title{
The Use of Magnetic Resonance Imaging and Plain Radiographs Among Adolescents With Back Pain and Adolescent Idiopathic Scoliosis
}

SOHRAB S. VIRK, WALTER P. SAMORA, FRANK M. PHILLIPS and SAFDAR N. KHAN

Int J Spine Surg 2018, 12 (2) 154-159

doi: https://doi.org/10.14444/5023

http://ijssurgery.com/content/12/2/154

This information is current as of April 26, 2023.

Email Alerts Receive free email-alerts when new articles cite this article. Sign up at:

http://ijssurgery.com/alerts

The International Journal of Spine Surgery

2397 Waterbury Circle, Suite 1,

Aurora, IL 60504, Phone: +1-630-375-1432 


\title{
The Use of Magnetic Resonance Imaging and Plain Radiographs Among Adolescents With Back Pain and Adolescent Idiopathic Scoliosis
}

\author{
SOHRAB S. VIRK, MD, MBA, ${ }^{1}$ WALTER P. SAMORA, MD ${ }^{2}$ FRANK M. PHILLIPS, MD ${ }^{3}$ SAFDAR N. \\ KHAN, MD ${ }^{1}$ \\ ${ }^{I}$ Department of Orthopaedics, Wexner Medical Center, The Ohio State University, Columbus, Ohio, ${ }^{2}$ Department of Orthopedic Surgery, Nationwide Children's \\ Hospital, Columbus, Ohio, ${ }^{3}$ Midwest Orthopaedics at Rush University, Chicago, Illinois
}

\begin{abstract}
Background: Low back pain (LBP) and adolescent idiopathic scoliosis (AIS) are common pediatric diagnoses. The workup for these diagnoses can be highly variable and can use significant health care resources. There has been no analysis to date on the use of imaging for workup of AIS and/or LBP.

Methods: The Humana Private Payer Database was queried for clinical and financial information for patients with AIS and/or LBP using International Classification of Diseases (ICD-9) for LBP and AIS. Current procedural terminology codes related to magnetic resonance imaging (MRI) and radiographs for the thoracolumbar spine were used to identify patients with LBP and/or AIS that used these diagnostic imaging modalities. Only patients ages 10 to 19 years were included in this analysis.

Results: The total number of patients with AIS and LBP was 18696 and 56 560, respectively. Thoracolumbar imaging was used within the workup for $71.76 \%$ and $45.53 \%$ of patients with AIS alone and LBP alone, respectively. MRI was used for $2.92 \%$ and $9.53 \%$ of patients with AIS alone and LBP alone, respectively. Radiographic imaging was used for $71.06 \%$ and $42.63 \%$ for AIS alone and LBP alone, respectively. There was minimal variation among regions in use of MRI for AIS. For patients with LBP, the diagnosis with the highest use of MRI was "sciatica" $(29.07 \%)$. Patients with both LBP and AIS had statistically higher rates of imaging (91.04\%), MRI (18.99\%), and radiographs (89.71\%). Among patients with an MRI, 20.87\% never had a radiograph. Reimbursement per patient for radiographs was $\$ 164$ and \$239 for AIS and LBP, respectively. Reimbursement per patient for MRI was \$1,263 and \$1,882 for AIS and LBP, respectively.
\end{abstract}

Conclusions: There is substantial use of both MRI and radiographs for adolescents with LBP and/or AIS. Clinicians should be aware of the impact these diagnostic tests have on the patient and the overall health care system.

Other \& Special Categories

Keywords: low back pain, adolescent idiopathic scoliosis, MRI, radiographs, resource allocation

\section{INTRODUCTION}

Low back pain (LBP) in adolescents is a common diagnosis, with estimates ranging from $2 \%$ to $18 \%$ of children having some form of LBP. ${ }^{1-3}$ Similarly, adolescent idiopathic scoliosis (AIS) among patients between the ages of 10 and 16 years has been estimated to be present in $2 \%$ to $4 \%$ of children. ${ }^{4}$ Given the high numbers of patients with these diagnoses, there have been standardized approaches to determine when to use imaging for treatment of AIS and LBP. For patients with AIS, there are certain clinical indications that may encourage a physician to obtain magnetic resonance imaging (MRI), but there are limited clinical signs or radiographic deformities that absolutely indicate for a MRI. ${ }^{5,6}$ LBP evaluation and treatment algorithms provide a guide for physicians when ordering radiographs and MRI for LBP. ${ }^{3,7,8}$ Within these studies for AIS and LBP, however, the authors acknowledge the significant rate of MRIs which yield relatively little diagnostic information.

The workup of AIS and LBP can, at times, place undue burden on the patient, patient families, and the overall health care system. It is widely accepted that a history and physical exam, as well as basic posteroanterior/lateral radiographs, are appropriate for initial workup of both AIS and LBP. ${ }^{5,6}$ Undue use of MRI for these patients is likely to incur unnecessary costs for the health care system as well as stress to the patient and patient's family without improvement in clinical outcomes. ${ }^{9}$ 
Table 1. CPT and ICD-9 codes for AIS and LBP.

\begin{tabular}{lcc}
\hline Diagnosis & ICD-9 Codes & $\begin{array}{c}\text { Descriptions of Select } \\
\text { Codes }\end{array}$ \\
\hline Low back pain & $\begin{array}{r}\text { ICD-9-D-7242, } \\
\text { ICD-9-D-8472, }\end{array}$ & $\begin{array}{c}\text { ICD-9-7242 = lumbago } \\
\text { (low back pain) }\end{array}$ \\
& ICD-9-D-7243, & ICD-9-7243 = sciatica \\
& ICD-9-D-7245, & \\
& ICD-9-D-7248, & \\
& ICD-9-D-7249, & \\
ICD-9-D-8472 & ICD-9-7373 = scoliosis \\
Idiopathic scoliosis & ICD-9-7373 & (and kyphoscoliosis) \\
& & idiopathic \\
\hline
\end{tabular}

Abbreviations: CPT, current procedural terminology; ICD-9, International Classification of Diseases; AIS, adolescent idiopathic scoliosis; LBP, low back pain.

The Humana Private Payer Database (HORTHO) is a collection of claims for all patients within the Humana insurance network with an orthopaedic-related diagnosis. This database has been used in a variety of clinical studies. ${ }^{10-13}$ The database provides an option for longitudinal tracking based on the date of a diagnosis, procedure, imaging event, lab result and/or a prescription medication. This function was useful for our particular analysis because it allowed us to track the amount of imaging paid for by Humana insurance after the diagnosis of AIS and/or LBP.

The goal of this study was to investigate the current use of imaging modalities for both AIS and LBP in patients between the ages of 10 and 19 years. Furthermore, we wanted to determine the influence of geographic location of patients on the use of radiographs and MRI. We also aimed to quantify the reimbursement associated with these diagnostic tests. Given the considerable expenses related to advanced imaging and the relatively low likelihood that these studies influence clinical treatment, the authors are concerned that there is overuse of resources for a portion of adolescents with AIS and/ or LBP. ${ }^{2}$ These expenses not only burden the health care system but may also expose young patients to high levels of radiation. We hope this study might encourage providers to be cautious when ordering these imaging studies for adolescents with AIS and/ or LBP.

\section{MATERIALS AND METHODS}

HORTHO was used to identify patients with AIS and LBP. We queried the database using software from PearlDiver (PearlDiver Technologies, Colorado Springs, Colorado). This database is compliant with all regulations associated with the Health
Table 2. CPT and ICD-9 codes for various imaging modalities for the thoracolumbar spine.

\begin{tabular}{|c|c|c|}
\hline $\begin{array}{l}\text { Imaging } \\
\text { Modality }\end{array}$ & CPT Code & $\begin{array}{c}\text { Descriptions of Select } \\
\text { Codes }\end{array}$ \\
\hline MRI & $\begin{array}{l}\text { CPT-72146, СРТ-72147, } \\
\text { СРT-72148, СРT-72149, } \\
\text { СРT-72157, СРT-72158 }\end{array}$ & $\begin{array}{l}\text { CPT-72146 = MRI } \\
\text { thoracic spine } \\
\text { CPT-72148 = MRI } \\
\text { lumbar spine } \\
\text { CPT-72149= MRI } \\
\text { lumbar spine with } \\
\text { contrast }\end{array}$ \\
\hline CT & $\begin{array}{l}\text { CPT-72128, СРT-72129, } \\
\text { CPT-72130, СРT-72131, } \\
\text { CPT-72132, CPT-72133, } \\
\text { CPT-71250, СРT-71260, } \\
\text { CPT-71270 }\end{array}$ & $\begin{array}{l}\mathrm{CPT}-72128=\mathrm{CT} \\
\text { thoracic spine } \\
\text { CPT-72131 = CT } \\
\text { lumbar spine }\end{array}$ \\
\hline Myelography & СРT-72265, СРТ-72270 & $\begin{array}{l}\text { CPT-72265 = } \\
\text { myelography } \\
\text { lumbosacral } \\
\text { radiologic supervision } \\
\text { and interpretation }\end{array}$ \\
\hline Radiographs & $\begin{array}{l}\text { CPT-72010, CPT-72020, } \\
\text { CPT-72069, CPT-72070, } \\
\text { CPT-72072, CPT-72074, } \\
\text { CPT-72080, CPT-72090, } \\
\text { CPT-72100, CPT-72110, } \\
\text { CPT-72114, CPT-72120, } \\
\text { CPT-72200, CPT-72202, } \\
\text { CPT-72220 }\end{array}$ & $\begin{array}{l}\text { CPT- } 72010= \\
\text { radiologic } \\
\text { examination spine } \\
\text { entire survey study } \\
\text { anteroposterior and } \\
\text { lateral } \\
\text { CPT-72069 = } \\
\text { radiologic } \\
\text { examination spine } \\
\text { thoracolumbar } \\
\text { standing (scoliosis) }\end{array}$ \\
\hline
\end{tabular}

Abbreviations: CPT, current procedural terminology; ICD-9, International Classification of Diseases; MRI, magnetic resonance imaging; CT, computed tomography.

Insurance Portability and Accountability Act (HIPAA) because all patient identifiers were removed from the database. We began our query by first identifying patients with AIS and LBP. This was done by searching for patients with an International Classification of Diseases (ICD-9) code related to either AIS and/or LBP. These ICD-9 codes are listed in Table 1. We filtered our cohort of patients to only include patients between ages 10 and 19 years.

We then queried the database to determine which patients obtained a thoracolumbar MRI, computed tomography (CT) scan, and/or a radiograph. We only included imaging modalities related to the thoracolumbar spine. The relevant current procedural terminology (CPT) codes for these imaging modalities are listed in Table 2. Of note, our query was designed in such a manner that patients with multiple radiographs would not affect our overall percentage of patients who had at least 1 thoracolumbar radiograph. For instance, patients with AIS who had multiple radiographs following progression of their scoliosis would only be counted once when determining what portion of patients with AIS had at least 1 radiograph. We also examined the 
Table 3. Breakdown of patient demographics with LBP and AIS.

\begin{tabular}{lcr}
\hline Patient Characteristic & AIS, \% & LBP, \% \\
\hline Sex & & \\
$\quad$ Male & 33.59 & 42.12 \\
Female & 66.41 & 57.88 \\
Region & & \\
Midwest & 26.42 & 30.48 \\
Northeast & 0.37 & 0.27 \\
South & 65.75 & 61.34 \\
West & 7.46 & 7.91 \\
Ages & & 30.44 \\
10-14 y & 51.82 & 69.56 \\
$15-19$ y & 48.18 & \\
\hline
\end{tabular}

Abbreviations: AIS, adolescent idiopathic scoliosis; LBP, low back pain.

time between diagnosis of AIS/back pain and either an MRI or radiograph. This time period is representative of when the first diagnosis is made and the first radiograph or MRI is obtained.

A $\chi^{2}$ test was used to compare the proportion of patients who had MRI or radiographic study between various cohorts of patients. Given that multiple comparisons would be performed, we used a Bonferroni correction factor in order to accurately determine statistically significant findings.

\section{RESULTS}

Between 2007 and 2015 there were 56650 and 18696 patients who received a diagnosis of LBP and AIS, respectively. The demographics for these patients are listed in Table 3. As expected, there were significantly more female patients receiving a diagnosis of AIS compared with male patients. Within the LBP cohort there were significantly more patients within the older (15-19 years) age group of patients.

The use of imaging within the LBP and AIS groups is shown in Table 4. Note that there was a significantly higher portion of patients who had radiographs for AIS compared with LBP. MRI, in contrast, was used at a higher rate for LBP patients than for AIS patients. A separate analysis was performed for patients with both LBP and AIS. These patients with a diagnosis of LBP and AIS had a rate of MRI use of $18.99 \%$, which was significantly higher $(P<.001)$ than for AIS or LBP

Table 4. Data regarding the portion of patients that had any type of imaging, MRI, or radiograph, for LBP, for AIS, and for both LBP and AIS.

\begin{tabular}{lccc}
\hline & AIS Alone, $\%$ & LBP Alone, $\%$ & AIS and LBP, \% \\
\hline Imaging & 71.76 & 45.37 & 91.04 \\
MRI & 2.92 & 9.53 & 18.99 \\
Radiographs & 71.06 & 42.63 & 89.71 \\
\hline
\end{tabular}

Abbreviations: LBP, low back pain; AIS, adolescent idiopathic scoliosis; MRI, magnetic resonance imaging.
Table 5. The rate of use of radiographs and MRI across geographic regions of the United States. ${ }^{a}$

\begin{tabular}{lcr}
\hline Region & AIS, \% & LBP, \% \\
\hline Radiographs & & \\
$\quad$ Midwest & 78.18 & 45.78 \\
Northeast & 63.77 & 38.96 \\
South & 76.30 & 48.66 \\
West & 72.60 & 40.95 \\
MRI & 7.51 & \\
$\quad$ Midwest & - & 9.88 \\
Northeast & 7.66 & 11.68 \\
South & 7.25 & 10.88 \\
West & & 9.12 \\
\hline
\end{tabular}

Abbreviations: MRI, magnetic resonance imaging; AIS, adolescent idiopathic scoliosis; LBP, low back pain; HIPAA, Health Insurance Portability and Accountability Act.

${ }^{a}$ Note that the rate of MRI for AIS patients is not shown because fewer than 11 patients within the Northeast had a MRI for AIS. Because of the need to protect the anonymity of patients and comply with rules set forth by HIPAA, no data point with fewer than 11 patients is shown within our analysis.

patients alone. Similarly, the rate of radiographs for patients with both LBP and AIS were significantly higher compared with the rates for AIS or LBP alone $(P<.001)$. Another query was performed to identify those patients with LBP who only had an MRI performed, without radiographs. The overall portion of LBP patients with MRI only was small at $2.18 \%$, but these patients did represent $20.87 \%$ of all LBP patients with an MRI.

A breakout analysis was performed to compare the rates of radiographs and MRI across regions within the HORTHO database. The results are shown in Table 5. The rate of MRI for AIS patients cannot be shown because of the fact that fewer than 11 patients within the Northeast had an MRI for AIS. Because of patient privacy regulations under HIPAA, no data point with fewer than 11 patients is shown within our analysis based on criteria mandated by PearlDiver Inc. Comparisons were made among each region in terms of use of radiographs and MRI for both LBP and AIS. There were no statistically significant differences in the use of MRI for AIS across regions. The only regions with statistically significant differences in MRI rates for LBP was between the Midwest and South $(P=.003)$ and the South and West $(P=.002)$.

Another breakout analysis was performed specifically on patients with LBP. We looked at which diagnoses related to LBP were associated with the highest rates of MRI use. We found that "sciatica" (ICD-9-7243) had the highest rate of MRI use (29.07\%). This was a statistically significant higher rate of use of MRI for all diagnoses except for "other unspecified back disorders" or ICD-9-7249. 
Table 6. The time between presentation and imaging is shown, as are the median values with both minimum and maximum durations between diagnosis and imaging.

\begin{tabular}{lcc}
\hline Diagnosis & $\begin{array}{c}\text { Time Between Diagnosis } \\
\text { and Radiographs, d, Median } \\
\text { (Minimum-Maximum) }\end{array}$ & $\begin{array}{c}\text { Time Between Diagnosis } \\
\text { and MRI, d, Median } \\
\text { (Minimum-Maximum) }\end{array}$ \\
\hline AIS & $126(1-1740)$ & $84(1-2259)$ \\
LBP & $74(1-2210)$ & $46(1-2307)$ \\
\hline
\end{tabular}

Abbreviations: MRI, magnetic resonance imaging; AIS, adolescent idiopathic scoliosis; LBP, low back pain.

This diagnosis was associated with a rate of $25.54 \%$ use of MRI ( $P=.064$ as compared with "sciatica").

The timing between patient presentation with back pain/AIS and imaging was examined simultaneously. These results are shown in Table 6. For those patients who did receive a radiograph for AIS, the median time to obtain radiographs was 126 days. MRIs for LBP had the shortest median duration between diagnosis and imaging. A similar query was performed for patients with AIS/LBP who had both an MRI and radiographs. For those patients with LBP who had both forms of imaging performed, the median time between LBP diagnosis and radiographs was 86 days, and median time was 48 days between LBP diagnosis and MRI. For those patients with AIS who had both MRI and radiographs, the median time between AIS diagnosis and radiographs was 108 days, and it was 96 days between AIS diagnosis and MRI.

Given the high rates of use of radiographs and MRI for these subsets of patients, an analysis of reimbursement was performed for both AIS and LBP. Radiographs for LBP and AIS were associated with $\$ 164$ and $\$ 239$ per patient reimbursement, respectively. MRIs for LBP and AIS were associated with $\$ 1882$ and $\$ 1263$ per patient reimbursement, respectively. Overall reimbursement for MRI was \$2 667058 and $\$ 7456874$ for AIS and LBP, respectively.

\section{DISCUSSION}

Our study finds that there is significant use of radiographs and MRI for both LBP and AIS patients. The rate of imaging of any type is higher for AIS patients $(77.35 \%)$ compared with LBP patients $(50.61 \%)$. MRI, however, is used at a higher rate of $10.44 \%$ for patients with LBP compared with AIS patients. The patients carrying a diagnosis of "sciatica" have the highest rate of MRI compared with other LBP diagnoses. Patients with a diagnosis of both AIS/LBP have significantly higher rates of MRI and radiographs compared with either LBP or AIS alone.

In evaluating LBP and AIS, initial history and physical exam are often supplemented with posteroanterior and lateral radiographs of the spine..$^{3,7,14}$ The referenced studies relate to establishing an algorithm for the treatment of LBP/AIS and were performed and published with the goal of educating the pediatrics community regarding the best way to efficiently evaluate LBP/AIS in children. All of these articles were published more than 5 years prior to the current data query. Therefore, it is interesting that within our study that a substantial portion of patients with LBP have an MRI. This may be due to aggressive workup of LBP in patients for whom there is a small chance that there is a cause of back pain that could be identified on radiographs/MRI. Similarly, it is not surprising that the shortest duration between diagnosis and imaging occurred for adolescent patients with LBP that required a MRI (median time to MRI was 46 days). This likely reflects the concern providers had for a cause of LBP for this cohort of patients that could be found on MRI. This is consistent with the most common diagnosis associated with MRIs for LBP being sciatica, which could be caused by a herniated disc or some other cause of lumbar stenosis. It is worrisome for the authors, however, that in more than $20 \%$ of patients with an MRI for LBP there were no radiographs prior to or after an MRI was performed. In this subset of patients, the ordering provider skipped a relatively inexpensive and quick exam (radiograph) for a more time-consuming and expensive advanced imaging modality. The authors of this study find it difficult to identify a clinical situation when a radiograph would not also be warranted if a physician is concerned enough about LBP to obtain an MRI. The reasons this overuse of advanced imaging continues will require further research.

There is ample evidence about the impact of geographic variation in the use of health care resources for end-of-life care, spine surgery, and use of advanced imaging. ${ }^{15-17}$ The data set that was used, however, does not have adequate representation from all geographic regions to allow for a proper analysis of geographic variations in workup of AIS/LBP. Although head-to-head comparisons did show statistically significant difference in MRI use for LBP between certain geographic regions, the overall use of MRI for LBP was largely similar among regions. Further research is required to 
properly define the geographic variations in workup and cost of workup for AIS/LBP for adolescents.

There are several significant limitations to this study. We relied on a retrospective database of clinical and financial information to form our conclusions. These data are based on ICD-9, DRG, and CPT codes, which are vulnerable to inaccuracies in billing. ${ }^{18}$ Still, hospitals and physicians are incentivized to bill accurately in order to avoid fraud and to be reimbursed appropriately. Furthermore, our study is based on data from a private payer health care database. There were no patients with Medicaid and/or coverage from the Children's Health Insurance Program (CHIP). There is evidence of a higher use of resources for patients with private payer insurance. ${ }^{19,20}$ Therefore, the actual use of imaging modalities like MRI may be higher in our patient population than for those children with government-subsidized health care coverage. Similarly, within the HORTHO database there is a smaller portion of patients from the Northeast. This reflects the fact that the HORTHO database is not a perfect representation of the demographics of the United States. We also did not analyze treatment modalities used between initial diagnosis of LBP and imaging. There is likely a cohort of patients who failed treatment with physical therapy, bracing, and/or activity modification. In this subgroup of patients, obtaining an MRI might be warranted. Further research is required to determine the clinical criteria/timing when MRI for adolescent LBP is appropriate.

Our study provides a breakdown of imaging modalities used for LBP and AIS. There is a higher rate of radiographs ordered for patients with AIS compared with LBP $(71.06 \%$ vs. $42.63 \%)$, whereas there is a higher rate of MRI for LBP compared with AIS (9.53\% vs. $2.92 \%)$. Those patients with LBP and AIS had a significantly higher rate of MRI (18.99\%) and radiograph $(89.71 \%)$ compared with either AIS or LBP alone. Rates of radiographs and MRI for LBP and AIS did vary to some degree, but overall use was similar among geographic regions. Further study is required to implement the highest-value algorithm for workup of AIS and LBP on a large national scale.

\section{REFERENCES}

1. Taimela S, Kujala UM, Salminen JJ, Viljanen T. The prevalence of low back pain among children and adolescents: a nationwide, cohort-based questionnaire survey in Finland. Spine. 1997;22(10):1132-1136.
2. Bernstein RM, Cozen H. Evaluation of back pain in children and adolescents. Am Fam Physician. 2007;76(11):1669-1676.

3. Ramirez N, Flynn JM, Hill BW, et al. Evaluation of a systematic approach to pediatric back pain: the utility of magnetic resonance imaging. J Pediatr Orthop. 2015;35(1):28-32.

4. Reamy BV, Slakey JB. Adolescent idiopathic scoliosis: review and current concepts. Am Fam Physician. 2001;64(1):111-116.

5. Maenza RA. Juvenile and adolescent idiopathic scoliosis: magnetic resonance imaging evaluation and clinical indications. J Pediatr Orthop B. 2003;12(5):295-302.

6. Davids JR, Chamberlin E, Blackhurst DW. Indications for magnetic resonance imaging in presumed adolescent idiopathic scoliosis. J Bone Joint Surg Am. 2004;86A(10):2187-2195.

7. Feldman DS, Straight JJ, Badra MI, Mohaideen A, Madan SS. Evaluation of an algorithmic approach to pediatric back pain. $J$ Pediatr Orthop. 2006;26(3):353-357.

8. Bhatia NN, Chow G, Timon SJ, Watts HG. Diagnostic modalities for the evaluation of pediatric back pain: a prospective study. J Pediatr Orthop. 2008;28(2):230-233.

9. Chou R, Fu R, Carrino JA, Deyo RA. Imaging strategies for low-back pain: systematic review and metaanalysis. Lancet. 2009;373(9662):463-472.

10. Bedard NA, Pugely AJ, Elkins JM, et al. The John N. Insall Award: do intraarticular injections increase the risk of infection after TKA? Clin Orthop Relat Res. 2017;475(1):45-52.

11. Howe A, Eyck LT, Dufour R, Shah N, Harrison DJ. Treatment patterns and annual drug costs of biologic therapies across indications from the Humana commercial database. $J$ Manag Care Pharm. 2014;20(12):1236-1244.

12. Lipman MD, Carstensen SE, Deal DN. Trends in the treatment of Dupuytren disease in the United States between 2007 and 2014. Hand (N Y). 2017;12(1):13-20.

13. Bedard NA, Pugely AJ, Duchman KR, Westermann RW, Gao Y, Callaghan JJ. When hip scopes fail, they do so quickly. J Arthroplasty. 2016;31(6):1183-1187.

14. Auerbach JD, Ahn J, Zgonis MH, Reddy SC, Ecker ML, Flynn JM. Streamlining the evaluation of low back pain in children. Clin Orthop Relat Res. 2008;466(8):1971-1977.

15. Deyo RA, Mirza SK. Trends and variations in the use of spine surgery. Clin Orthop Relat Res. 2006;443:139-146.

16. Wennberg JE, Fisher ES, Goodman DC, Skinner JS. Tracking the Care of Patients with Severe Chronic Illness: The Dartmouth Atlas of Health Care 2008. Hanover, NH: The Trustees of Dartmouth College. https://www.dartmouthatlas. org/downloads/atlases/2008_Chronic_Care_Atlas.pdf. Accessed June 30, 2016.

17. Pransky G, Foley G, Cifuentes M, Webster BS. Geographic variation in early MRI for acute work-related low back pain and associated factors. Spine. 2015;40(21):1712-1718.

18. Bozic KJ, Chiu VW, Takemoto SK, et al. The validity of using administrative claims data in total joint arthroplasty outcomes research. J Arthroplasty. 2010;25(6 suppl):58-61.

19. Chernew ME, Sabik LM, Chandra A, Gibson TB, Newhouse JP. Geographic correlation between large-firm commercial spending and Medicare spending. Am J Manag Care. 2010;16(2):131-138.

20. Elixhauser A, Machlin SR, Zodet MW, Chevarley FM, Patel N, McCormick MC, et al. Health care for children and youth 
in the United States: 2001 annual report on access, utilization, quality, and expenditures.Ambul Pediatr.2002;2(6):419-437.

Disclosures and COI: The authors received no funding for this study and report no conflicts of interest.

Corresponding Author: Safdar N. Khan, MD, Division of Spine Surgery, Department of Orthopaedics, The Spine Institute, 725 Prior Hall,
The Ohio State University, Columbus, OH. Phone: (614) 293-0706; Fax: (614) 293-2053; Email: safdar. khan@osumc.edu.

Published 3 August 2018

This manuscript is generously published free of charge by ISASS, the International Society for the Advancement of Spine Surgery. Copyright (C) 2018 ISASS. To see more or order reprints or permissions, see http://ijssurgery.com. 